\title{
Dimensional Changes in Periodontium with Immediate Replacement of Tooth by Socket Shield Technique: Two-year Follow-up
}

\author{
${ }^{1}$ Farhan Durrani, ${ }^{2}$ Dhananjay S Yadav, ${ }^{3}$ Arpit Galohda, ${ }^{4}$ Patricia Ome Borang , ${ }^{5}$ Faizia Rahman
}

\begin{abstract}
Extraction socket healing and osseous remodeling take 120 to 180 days. Healing results in $50 \%$ reduction in the buccolingual bone in 12 months. Buccal bone loss of the extraction socket exceeds more than two-thirds with reduction in apicocoronal height by approximately $0.8 \mathrm{~mm}$ within 3 months of healing. Bundle bone is the portion of alveolar bone where fibers from the periodontal ligament (PDL) insert. A clinical technique was developed to preserve the bundle bone and the surrounding PDL through retention of buccal tooth root portion. This clinical case describes about immediate tooth replacement with an implant by preserving the buccal root in the anterior maxillary region with a 2-year follow-up. The hard tissue comparative correlation pre- and postoperative was measured using multislice computed tomography scanner (MSCT) and soft tissue by pink esthetic score (PES). The result after 2 years of evaluation was promising with negligible changes in hard and soft tissues. The study predicts encouraging results for immediate replacement of hopeless tooth in anterior maxilla without the use of augmentation materials. The surgeon should be experienced as the skills require expertise and knowledge.
\end{abstract}

Keywords: Buccal bone, Esthetic zone, Extraction socket, Immediate implant, Socket shield.

How to cite this article: Durrani F, Yadav DS, Galohda A, Borang PO, Rahman F. Dimensional Changes in Periodontium with Immediate Replacement of Tooth by Socket Shield Technique: Two-year Follow-up. Int J Oral Implantol Clin Res 2017;8(1):17-21.

\section{Source of support: Nil}

Conflict of interest: None

\section{BACKGROUND}

Sufficient alveolar bone volume and favorable architecture of the alveolar ridge are essential to obtain ideal functional and esthetic prosthetic reconstruction following implant therapy. ${ }^{1}$ Within 12 months of tooth extraction, the width of the alveolar ridge reduces by $50 \%$ during the

\footnotetext{
${ }^{1}$ Associate Professor and Head, ${ }^{2-5}$ Postgraduate Student

${ }^{1-5}$ Department of Periodontics, Faculty of Dental Sciences Institute of Medical Sciences, Banaras Hindu University, Uttar Pradesh, India

Corresponding Author: Farhan Durrani, Associate Professor and Head, Department of Periodontics, Faculty of Dental Sciences, Institute of Medical Sciences, Banaras Hindu University, Uttar Pradesh, India, Phone: +919335873366, e-mail: docfarhan@rediffmail.com
}

observation period. The loss corresponds to 5 to $7 \mathrm{~mm}$ as reported in earlier studies. ${ }^{2}$ The reduction of alveolar bone volume following tooth extraction may interfere with the placement of implants. Even with the introduction of traumatic techniques for socket preservation and advances in biomaterials used in conjugation with these techniques, ridge resorption can only be partially countered. ${ }^{3}$ Especially in the areas of esthetic importance, the preservation of peri-implant tissues has been the biggest challenge in the field of implant dentistry and can only be achieved in select few cases depending upon the etiology of tooth loss. In an attempt to overcome these challenges, researchers started preserving the ridges by maintaining the natural attachment apparatus of tooth. The loss of the PDL and bundle bone plays a major role in influencing the resorption process resulting in subsequent peri-implant soft tissue recession and esthetic deterioration. This led to the development of a root submergence technique; however, it was utilized for maintaining ridge morphology for complete dentures and for pontic site development. ${ }^{4}$ A technique called socket shield was adopted for preservation of periodontium on the buccal side of extracted socket by partial retention of the root. ${ }^{5}$ Retaining the buccal aspect of the root during implant placement did not appear to interfere with osseointegration. The aim of this clinical case was to evaluate hard and soft tissue changes 2 years postoperatively. For hard tissue analysis, the 64 slice MSCT (GE, Philips, Siemens, Toshiba) cross-sections were used. Pink esthetic score was employed for soft tissue analysis. The follow-up study of socket shield technique highlights the preservation of hard and soft tissue architecture, which may have been achieved by multiple surgeries and expensive bio engineering materials.

\section{CLINICAL CASE PRESENTATION}

A 22-year-old male presented to the Faculty of Dental Sciences, Institute of Medical Sciences in connection with poor state of both upper central incisors. The fractures of central incisors were complicated with right central, the caries extending to the gingival margin, but the root looked intact and healthy. Clinical examination showed healthy attached gingiva and normal biotype with mild calculus 
on lower anterior dentition. The marginal gingiva of both upper anterior teeth were inflamed because of temporary acrylic crowns that were cemented on them. There were residues visible on left incisor, as it was taken as abutment for a cantilever bridge. Oral hygiene was acceptable.

The patient was referred to endodontic specialist to evaluate both the teeth for their vitality and possible methods of saving them. Tooth number 11 was restorable, but tooth number 21 looked hopeless because of the extension of caries subgingivally. The unexpected outcome led to the consultation with the patient for the extraction of 21 and if possible, immediate replacement with an implant. As we received the consent for the implant-retained prosthesis, oral hygiene was reinforced and an impression was taken for initial wax up and fabrication of surgical template.

The patient was a medically healthy adult and a nonsmoker. The hopeless teeth had intact buccal bone, with normal periodontal biotype. The experiment was undertaken with understanding of the procedure by the patient and a written consent. To overcome expected postextraction ridge resorption, PDL-mediated root preservation technique was planned with simultaneous implant placement. Preoperative scan evaluation indicated sufficient width palatal to the facial root resection to accommodate 3.4 by $13 \mathrm{~mm}$ (XiveDentsply) with an option of screw- or cement-retained prosthesis. The adjacent teeth would be restored with IPS e.max (Lithium Disilicate, Ivoclar) crown after asymptomatic root canal treatment.

\section{SURGICAL PROCEDURE}

The surgical guide template was fabricated after diagnostic wax up of the missing incisor with adequate stops. Patient was anesthetized with infiltration technique (lignocaine hydrochloride 1;80,000 adrenaline, Intra Labs Pvt Ltd) above the root of tooth number 21. After adequate numbness, the coronal part of the tooth was cut horizontally with straight fissure bur and removed atraumatically. The root was sectioned mesiodistally along the long axis of tooth as far as apically possible with the help of long shank root resection bur locked in hydrated high speed hand piece (SS White the Master Kit). Radoivisuography at every interval of the procedure was used to confirm the depth of the cuts. Periotomes severed the PDL between palatal root and lingual part of the socket and the remaining part was carefully removed in a way not to disturb the facial root section. The coronal part of buccal root was reduced subgingivally, but kept $1 \mathrm{~mm}$ above the alveolar crest. It was also beveled toward the implant to create more space for soft tissue between abutment and dentin (Fig. 1).

After completion of all the steps, sequential osteotomy for 3.4/13 mm, internal connection implant (Xive, Dentsply) was prepared on the palatal wall of the socket.
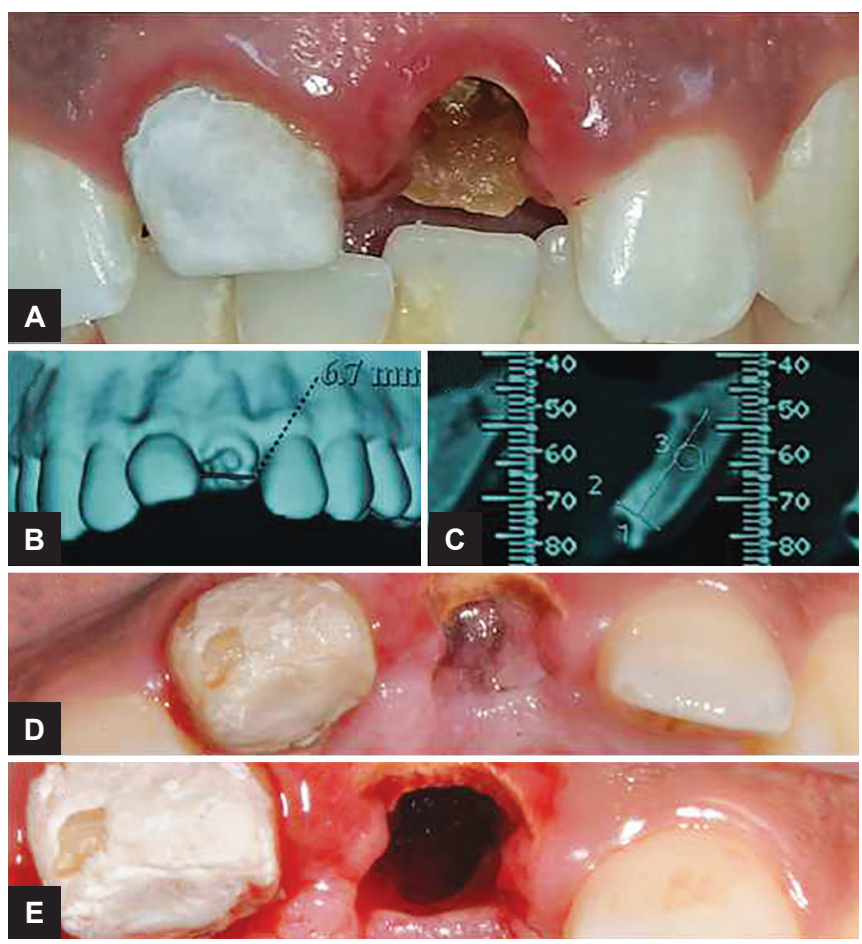

Figs 1A to E: (A) Horizontal tooth fracture 21 with cement residues on 11; (B) scan shows adequate palatal bone with no periapical pathosis; (C) cross-sectional view; (D) occlusal view; and (E) buccal section of the root visible

The implant was kept $3 \mathrm{~mm}$ below the free gingival margin. In an unlikely event if the buccal portion of the root gets dislodged, implant placement will continue in a conventional manner. The jump gap was filled with a bovine bone graft (cerabone, Biotiss Biomaterials). Some studies have not used any graft at all. Because of less implant stability quotient recordings on Ostell (Sweden) for the implant, modified gingival former (GH2, Friadent) was tightened on the implant. Failure to do this would have the socket shield not covered by the soft tissue. Postsurgical instructions included antibiotics amoxyclav $625 \mathrm{mg}$ twice daily for 5 days and analgesic (Ibuprofen $400 \mathrm{mg}$ ) as per pain. The patient was told to defer tooth brushing for a week in the surgical area and avoid any trauma. Oral hygiene was reinforced through regular tooth brushing twice daily and chlorhexidine (Clohex Plus, 0.02\%; Dr Reddy Laboratories) mouthwash three times daily. Patient was recalled every 3 weeks for a period of 4 months (Fig. 2).

\section{PROSTHETIC PROCEDURE}

The tooth number 11 was prepared for full coverage crown after asymptomatic root canal treatment. The peri-implant mucosa of 21 after 4 months was completely healed and the socket was covered by the soft tissue. The most challenging aspect of implant dentistry is to have a pleasing soft tissue architecture, especially in anterior esthetic area. Accurate transfer of the impression to the technician by the 

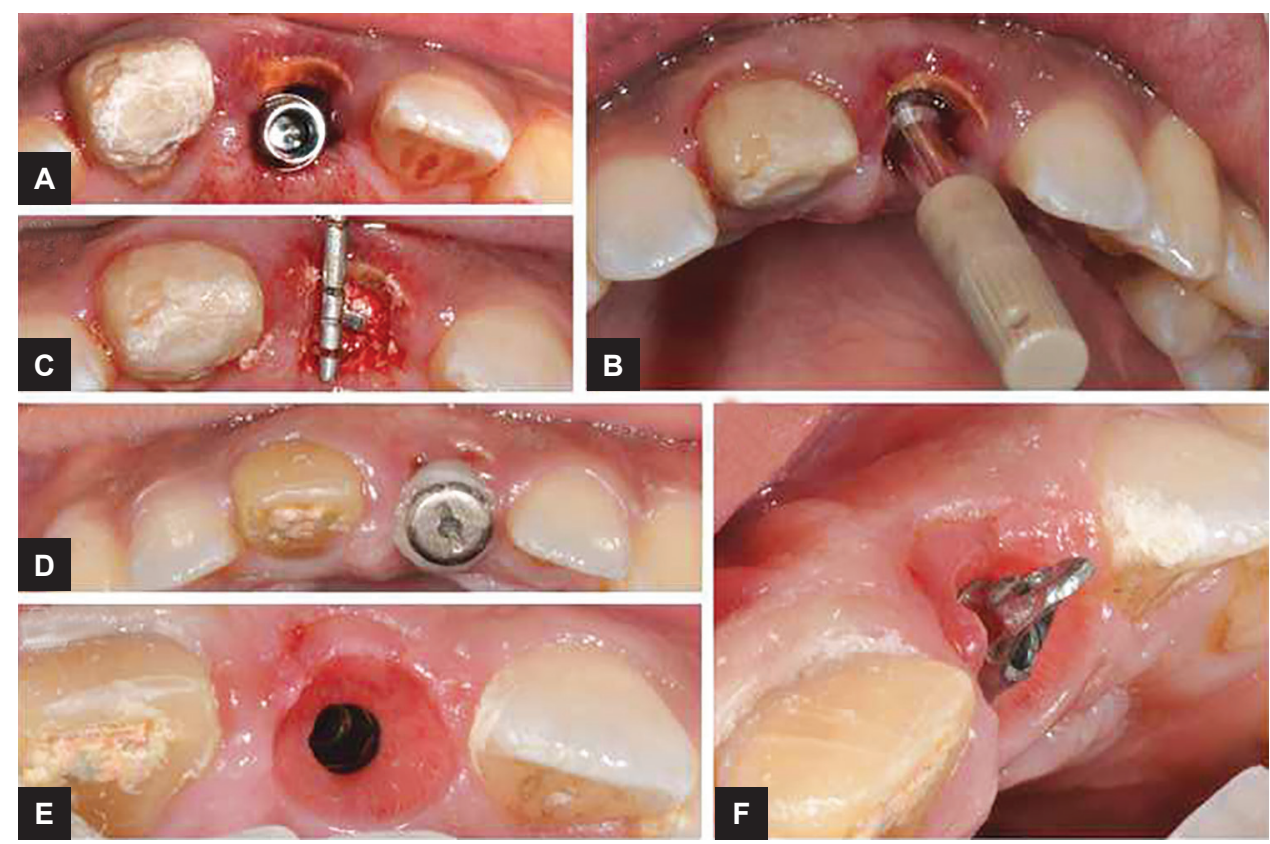

Figs 2A to F: (A) Implant placement; (B) ostell check; (C) bone graft around the implant; (D) modified gingival former; (E) gingival contour visible after removal of healing screw; and (F) angulated abutment placed

dentist requires meticulous steps. A highly accurate profile measurement will enhance the predictability of the final outcome. Gingival architecture created by modified healing of the former had to be quickly transferred by the clinician in order to prevent the flattening of the tissues. In our case, we used the angled abutment (Xive Esthetic Base, Dentsply) instead of reduced size of impression post to transfer the impression. After attaching the abutment and radiographic check of no microgap, the empty spaces were filled with low shrinkage acrylic (GC Pattern Resin ${ }^{\mathrm{TM}}$ LC GC America) all around, ensuring the facial position with the mark. Blanching was allowed before the impression. The impression was taken with Addition Silicone (Aquasil Ultra-Dentsply) using closed tray method. Custom healing screw was placed back on the implant (Fig. 3). After delivery of all ceramic crowns (IPS e.max Ceram, Ivoclar), they were cemented on the abutment and adjacent incisor with esthetic resin cement (Rely $\mathrm{X}^{\mathrm{TM}}$ Ultimate Clicker) as per routine protocols. The occlusion was checked with proper anterior guidance and bilateral posterior disocclusion (Fig. 4).

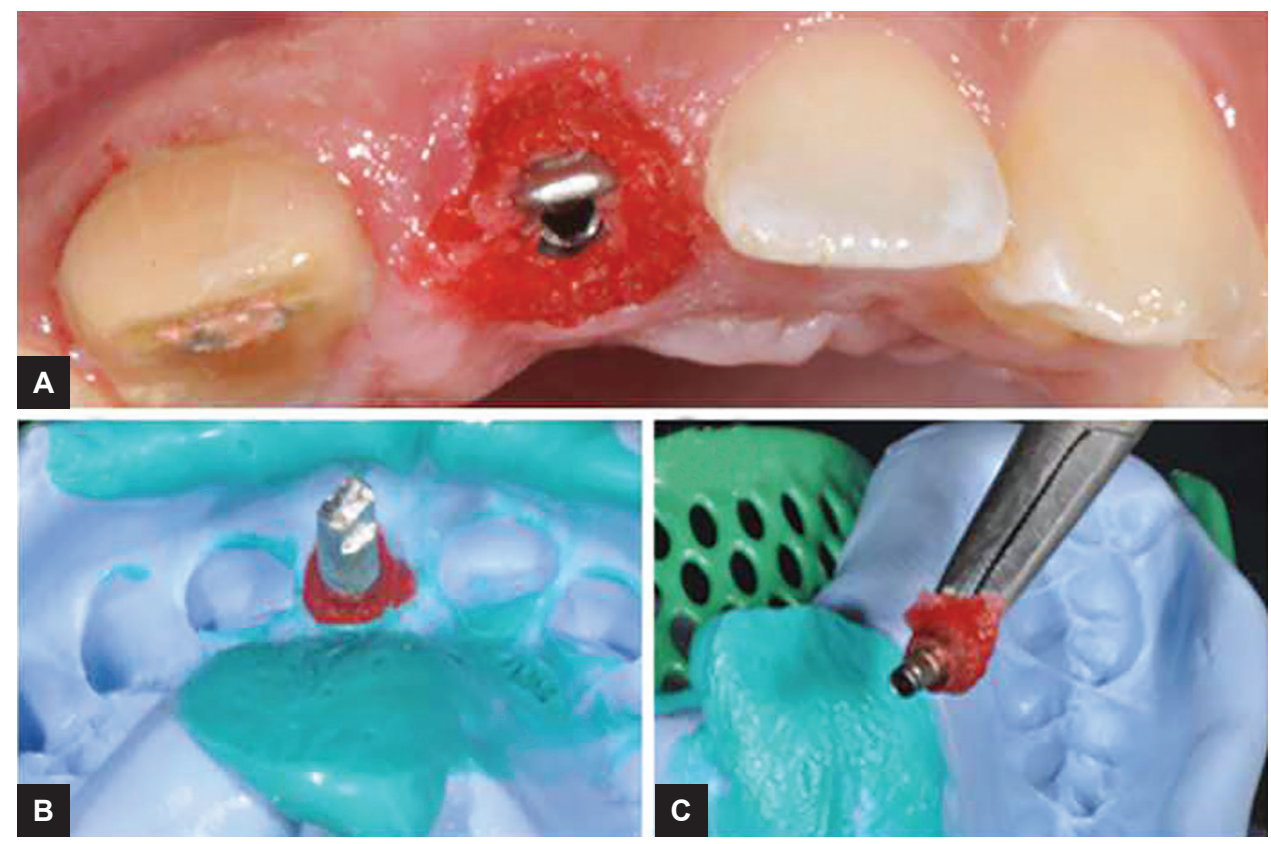

Figs 3A to C: (A) Xive Esthetic Base angled abutment surrounded by pattern resin; (B) direct impression taken with addition silicone with analog attached; and $(C)$ abutment unscrewed with captured subgingival profile 


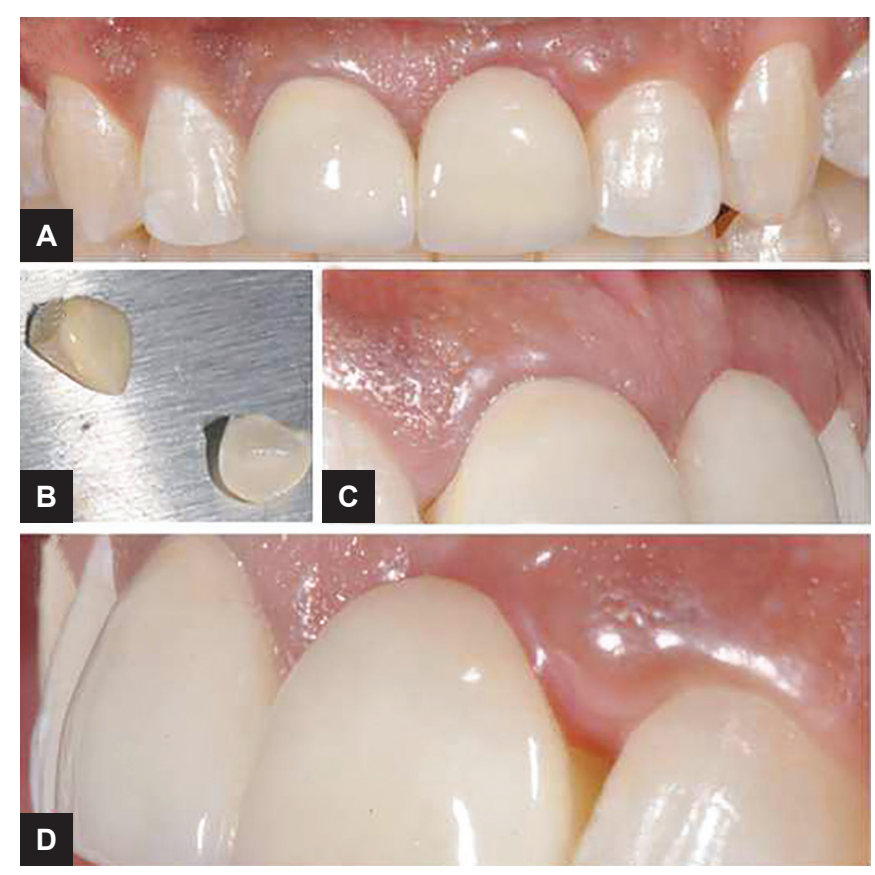

Figs 4A to D: (A) Cementation of esthetic e.max crowns; (B) two lithium disilicate crowns (IPS e.max, Ivoclar); (C) visible buccofacial tissue_right side; and (D) visible buccofacial tissue_left side

The patient was kept on regular recall program for 2 years to check the pink esthetics and its changes were visible through subjective outcomes. To check the periimplant health, measurements, such as probing depth, bleeding on probing, and buccal width of keratanized mucosa were analyzed. The mucogingival junction can be easily assessed by staining of mucogingival complex by Lugol's iodine solution. The alveolar mucosa differs from keratanized gingiva due to its glycogen content.
The attached gingiva which is keratanized has no glycogen content in the superficial layer, so it gives a negative response. The 3D volumetric evaluation of buccal and palatal cortical bones was done with MSCT. The crosssectional slice showed the presence of buccal cortical plate with retained root section without any remodeling 2 years postoperatively. The presence of attached gingiva even after 2 years was without any collapse of buccofacial tissues giving a promising result for the future esthetic immediate implant replacement without the use of expensive regenerative tissue engineering (Fig. 5).

\section{DISCUSSION}

In the early 1990s, Buser et al ${ }^{6,7}$ attempted to introduce a new concept-implants surrounded by PDL. A very important observation was made; the portion of the implant that was in contact with the retained portion of the root was covered by a layer of cementum populated by collagen fibers. Further studies showed that the immediate implant placement with intentional preservation of buccal portion of the tooth root may be an approach that leads to preservation of the blood supply of the buccal plate and consequent preservation of the dimensions of alveolar ridge. ${ }^{5}$ Following the tooth extraction, the tissue resorbs as a direct result of the bundle bone-PDL tooth complex. Bundle bone arises from functionally loaded PDL and its loss following tooth extraction results in a certain collapse of residual bucco-facial tissues. ${ }^{8}$ The implant rehabilitation of a tooth with hopeless prognosis in the esthetic zone is still a debatable treatment despite several systemic reviews. ${ }^{9}$ After tooth extraction, there are alterations in
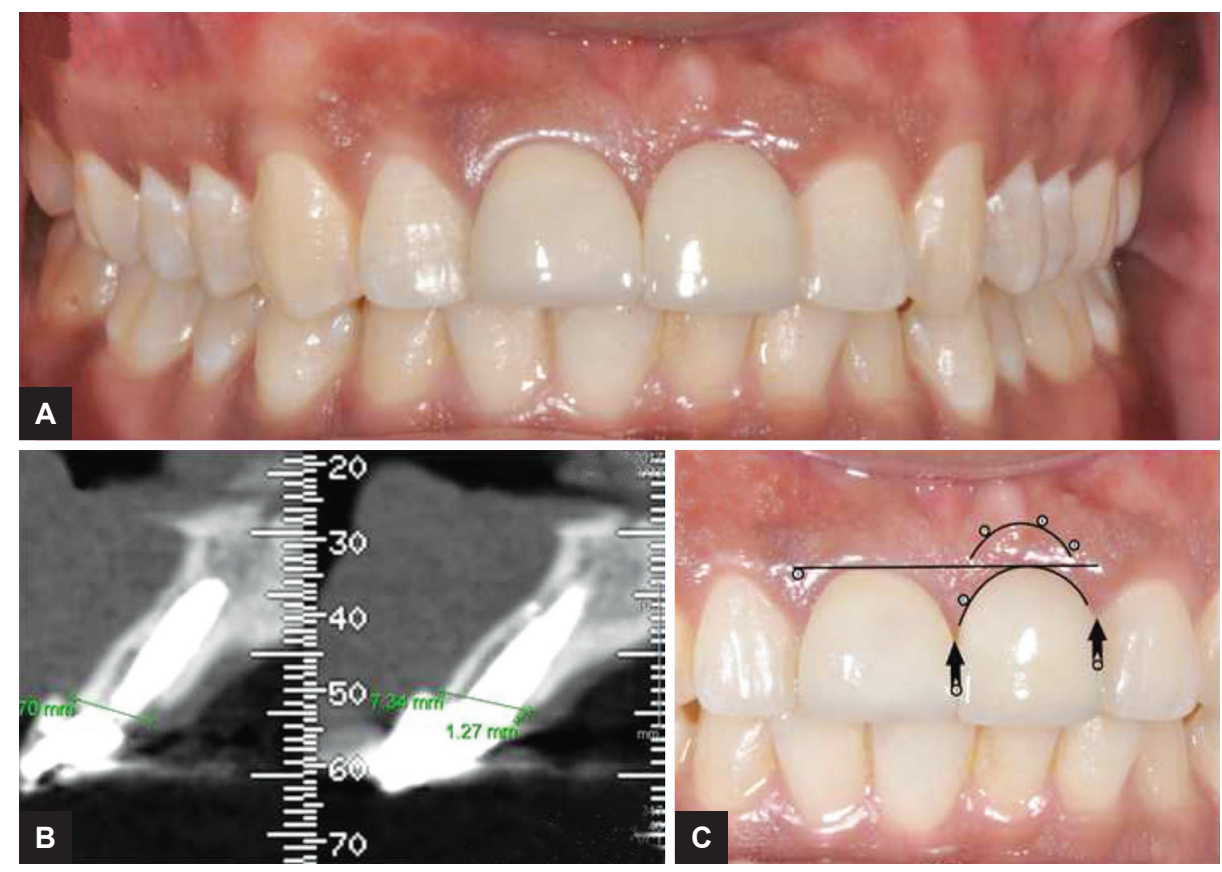

Figs 5A to C: (A) Postoperative preview picture after 2 years; (B) cross-section slice with visible buccal shield; and (C) PES measurement analysis 
bony architecture with apical migration of soft tissues. Several interventions have been advocated for achieving esthetic soft tissue profile. These include biomaterials, autogenous tissue grafts, advanced surgical techniques, and a combination of these. ${ }^{10} \mathrm{~A}$ wealth of literature supports these ridge management techniques, but shrinkage of tissues with healing has always been a complication.

In our clinical case, the PDL-mediated buccal root preservation technique preserved the buccofacial tissues for 2 years through blood and cellular supply that stems from PDL. Although scientific evidence of the described technique is still lacking, it does offer advantages in immediate implant placement. Predictable esthetics can be achieved without loss of soft and hard tissues. On distal aspect of implant crown, there was recession of papilla; the reason could be unknown as it has been reported in several studies. ${ }^{11,12}$ However, there is papilla rebounding over a period of time. Modified socket shield technique for interimplant papilla preservation, where shield was located more in interproximal than buccal area, was also successful in maintaining the esthetic periodontium around the teeth. ${ }^{13}$

In our case, the remaining tooth structure showed healthy PDL at buccal side without osteoclastic remodeling. However, the case selection is very important; teeth with recession, periodontal disease, or attachment loss are not treated with this technique as preoperative tissue level will dictate the final outcome. Further, horizontal root fractures that extend subcrestally at the facial aspect are contraindicated because benefit of retention of coronal aspect of the root for attachment of soft tissues is eliminated. ${ }^{14}$ Recent studies on socket shield technique with 5 years follow-up had 100\% survival rate and low rate of crestal bone loss on mesial and distal sides. There was a single reported apical resorption of the shield due to microbial leftovers on the root. ${ }^{15}$ However, our results look promising after 2 years. The PES was 11 with very slight mucosal recession and not complete coverage of distal papilla interdentally. The papilla may recover after a period of 5 years. The technique completely preserved the buccofacial tissues with no change in keratinization. The collapse of buccal contour was negligible and soft tissue esthetics looked quite promising.

\section{CONCLUSION}

The PDL-mediated root membrane technique may be the future of esthetics with hard and soft tissue volume maintenance. However, long-term randomized controlled trials with a large number of subjects are required with a minimum 10-year follow-up for proper assessment of the technique. However, our clinical case described good buccal bone thickness with no mucosal recession and acceptable esthetics. It was a 2-year follow-up study with an encouraging result, the subjective outcome from the clinician and patient prospective points of view looks acceptable with avoidance of multiple surgeries and negligible use of expensive tissue engineering products.

\section{REFERENCES}

1. Schneider R. Prosthetic concerns about atrophic alveolar ridges. Postgrad Dent 1999 Feb;6(2):3-7.

2. Lekovic V, Kenney EB, Weinlaender M, Han T, Klokkevold P, Nedic M, Orsini M. A bone regenerative approach to alveolar ridge maintenance following tooth extraction. Report of 10 cases. J Periodontol 1997 Jun;68(6):563-570.

3. Kotsakis GA, Salama M, Chrepa V, Hinrichs JE, Gaillard P. A randomized, blinded, controlled clinical study of particulate anorganic bovine bone mineral and calcium phosphosilicate putty bone substitutes for alveolar ridge preservation. Int J Oral Maxillofac Implants 2014 Jan-Feb;29(1):141-151.

4. Salama M, Ishikawa T, Salama H, Funato A, Garber D. Advantages of the root submergence technique for pontic site development in esthetic implant therapy. Int J Periodontics Restorative Dent 2007 Dec;27(6):521-527.

5. HürzelerMB,ZuhrO, SchupbachP, RebeleSF, EmmanouilidisN, FicklS. The socket-shield technique: a proof-of-principle report. J Clin Periodontol 2010 Sep;37(9):855-862.

6. Buser D, Warrer K, Karring T. Formation of a periodontal ligament around titanium implants. J Periodontol 1990 Sep;61(9):597-601.

7. Buser D, Warrer K, Karring T, Stich H. Titanium implants with a true periodontal ligament: an alternative to osseointegrated implants? Int J Oral Maxillofac Implants 1990 Summer;5(2):113-116.

8. Ho SP, Kurylo MP, Grandfield K, Hurng J, Herber RP, Ryder MI, Altoe V, Aloni S, Feng JQ, Webb S, et al. The plastic nature of the human bone periodontal ligament-tooth fibrous joint. Bone 2013 Dec;57(2):455-467.

9. Chen ST, Buser D. Esthetic outcomes following immediate and early implant placement in the anterior maxilla-a systematic review. Int J Oral Maxillofac Implants 2014;29(Suppl):186-215.

10. Lin GH, Chan HL, Wang HL. Effects of currently available surgical and restorative interventions on reducing midfacial mucosal recession of immediately placed single implants: a systemic review. J Periodontal 2014 Jan;85(1):92-102.

11. Boardman N, Darby I, Chen S. A retrospective evaluation of aesthetic outcomes for single-tooth implants in the anterior maxilla. Clin Oral Implants Res 2016 Apr;27(4):443-451.

12. Gallucci GO, Grütter L, Chuang SK, Belser UC. Dimensional changes of peri-implant soft tissue over 2 years with singleimplant crowns in the anterior maxilla. J Clin Periodontol 2011 Mar;38(3):293-299.

13. Kan JY, Rungcharassaeng K. Proximal socket shield for interimplant papilla preservation in the esthetic zone. Int J Periodontics Restorative Dent 2013 Jan-Feb;33(1):e24-e31.

14. Mitsias ME, Siormpas KD, Kontsiotou-Siormpa E, Prasad H, Garber D, Kotsakis GA. A step-by-step description of PDLmediated ridge preservation for immediate implant rehabilitation in the esthetic region. Int J Periodontics Restorative Dent 2015 Nov-Dec;35(6):835-841.

15. Siormpas KD, Mitsias ME, Kontsiotou-Siormpa E, Garber D, Kotsakis GA. Immediate implant placement in the esthetic zone utilizing the "root-membrane" technique: clinical results up to 5 years postloading. Int J Oral Maxillofac Implants 2014 Nov-Dec;29(6):1397-1405. 